\title{
Arsenic mobilization in spent nZVI waste residue: Effect of Pantoea sp. $\mathrm{IMH}^{\text {出 }}$
}

\author{
Li Ye $^{\mathrm{a}, \mathrm{b}}$, Wenjing Liu ${ }^{\mathrm{a}, \mathrm{b}}$, Qiantao Shi ${ }^{\mathrm{a}, \mathrm{b}}$, Chuanyong Jing ${ }^{\mathrm{a}, \mathrm{b}, *}$ \\ a State Key Laboratory of Environmental Chemistry and Ecotoxicology, Research Center for Eco-Environmental Sciences, Chinese Academy of Sciences, \\ Beijing 100085, China \\ ${ }^{\mathrm{b}}$ University of Chinese Academy of Sciences, Beijing 100049, China
}

\section{A R T I C L E I N F O}

\section{Article history:}

Received 10 March 2017

Received in revised form 19 July 2017

Accepted 21 July 2017

Available online 28 July 2017

\section{Keywords:}

Arsenic

Spent nZVI

arsC gene

Bio-transformation

Spectroscopy

\begin{abstract}
A B S T R A C T
Nanoscale zero-valent iron (nZVI) is an effective arsenic (As) scavenger. However, spent nZVI may pose a higher environmental risk than our initial thought in the presence of As-reducing bacteria. Therefore, our motivation was to explore the As redox transformation and release in spent nZVI waste residue in contact with Pantoea sp. IMH, an arsC gene container adopting the As detoxification pathway. Our incubation results showed that IMH preferentially reduce soluble $\mathrm{As}(\mathrm{V})$, not solid-bound $\mathrm{As}(\mathrm{V})$, and was innocent in elevating total dissolved As concentrations. $\mu$-XRF and As $\mu$-XANES spectra clearly revealed the heterogeneity and complexity of the inoculated and control samples. Nevertheless, the surface As local coordination was not affected by the presence of IMH as evidenced by similar As-Fe atomic distance (3.32 $-3.36 \AA$ ) and coordination number (1.9) in control and inoculated samples. The Fe XANES results suggested that magnetite in nZVI residue was partly transformed to ferrihydrite, and the IMH activity slowed down the nZVI aging process. IMH distorted Fe local coordination without change its As adsorption capacity as suggested by Mössbauer spectroscopy. Arsenic retention is not inevitably enhanced by in situ formed secondary Fe minerals, but depends on the relative As affinity between the primary and secondary iron minerals.
\end{abstract}

๑) 2017 Elsevier Ltd. All rights reserved.

\section{Introduction}

Nanoscale zero-valent iron (nZVI) has been widely used in arsenic (As) remediation in wastewater and contaminated soil because of its large specific surface area and high surface reactivity (Cao et al., 2016; Gil-Diaz et al., 2014; Li et al., 2017; Tosco et al., 2014). nZVI is readily oxidized and the subsequent iron corrosion products such as ferrous/ferric (hydr)oxides are responsible for As adsorption (Mak et al., 2011; Yan et al., 2012). This As-laden or spent nZVI may oxidize and gradually crystallize over time to more ordered forms such as magnetite, maghemite and other iron minerals (Calderon and Fullana, 2015). Because of the natural occurrence of iron and its corrosion products, nZVI is designed for direct use and is disposed of in the environment (Bruton et al., 2015). However, recent studies suggest that the aging of nZVI may facilitate the

\footnotetext{
* This paper has been recommended for acceptance by Dr. Jorg Rinklebe.

* Corresponding author. State Key Laboratory of Environmental Chemistry and Ecotoxicology, Research Center for Eco-Environmental Sciences, Chinese Academy of Sciences, Beijing 100085, China.

E-mail address: cyjing@rcees.ac.cn (C. Jing).
}

heavy metal release and the secondary environmental pollution (Calderon and Fullana, 2015; Cohen et al., 2016; Yin et al., 2012), especially when spent nZVI is left unattended at treated sites (Kim et al., 2010; Yin et al., 2012).

Microorganisms play a prominent role in the redox transformation and mobilization of As through the change in As speciation and Fe(III) oxide dissolution (Mumford et al., 2012; Tian et al., 2015; Zhang et al., 2012). Bacteria can reduce As(V) either by an anaerobic respiratory pathway mediated by arrA genes or by an aerobic detoxification pathway mediated by arsC genes (Murphy and Saltikov, 2009; Wang et al., 2017). Recent studies adopted the aeration process in nZVI treatment to enhance As removal due to the formation of Fe (hydr)oxides (Simon et al., 2016; Tanboonchuy et al., 2011; Yang et al., 2016), therefore, the aerobic As-reducing bacteria with arsC genes may play a central role in As biomobilization. However, whether arsC gene containers can directly reduce adsorbed $\mathrm{As}(\mathrm{V})$ remains unclear. For example, a possible arsC carrier, Clostridium sp. CN8 (Langner and Inskeep, 2000), was observed to rapidly reduce dissolved $\mathrm{As}(\mathrm{V})$, but not adsorbed $\mathrm{As}(\mathrm{V})$ on ferrihydrite. The authors concluded that the reduction of aqueous $\mathrm{As}(\mathrm{V})$ had a minor effect on As desorption. In contrast, a 
recent study, using two arsC carriers, Pseudomonas sp. M17-1 and Bacillus sp. M17-15 (Guo et al., 2015), found the occurrence of As(III) on the initially $\mathrm{As}(\mathrm{V})$ occupied goethite surface, suggesting direct reduction for adsorbed $\mathrm{As}(\mathrm{V})$.

The Fe(III) oxide dissolution leads to As mobilization (LeMonte et al., 2017), but subsequently in situ formed secondary iron minerals are reported to re-uptake As (Islam et al., 2005). Most previous studies found that As retention is actually enhanced during the formation of secondary Fe minerals (Table S1). However, limited knowledge is available about the iron transformation in spent nZVI in the presence of arsC carriers. In addition, the impact of iron transformation in spent nZVI for As retention is unknown. The desire to decipher the coupled biotransformation of As and nZVI by ars $C$ carriers motivates our study.

The purpose of this study was to explore As and Fe redox transformation and release in spent nZVI waste residue in the presence of an aerobic As(V)-reducing bacterium, Pantoea sp. IMH. This genus is widespread in various environmental conditions (Meng et al., 1995; Zhang and Birch, 1997), and IMH contains two ars operons with high As resistance capacity (Wang et al., 2016). The spent nZVI waste residue used in this study was collected in a rare metal smelting company in China where nZVI was used to remove As from wastewater. Multiple complementary techniques including incubation experiments, X-ray absorption fine structure (XAFS) and Mössbauer spectroscopy were employed to characterize the reaction process. The insights gained from this study shed new light on the risk assessment of nZVI waste residue in the environment.

\section{Material and methods}

\section{1. $n Z V I$ waste residue}

nZVI was used in As removal from a wastewater by a rare metal smelting company in China. The wastewater contained $192 \mathrm{mg} / \mathrm{L}$ As(V) and $3.3 \mathrm{mg} / \mathrm{L} \mathrm{Fe}$ at pH 6.9 (Yan et al., 2016). To determine the total metal content in spent nZVI, triplicate samples were freezedried and then digested with a microwave digestion system for metal analysis (MARS, CEM Corporation, U.S.) (Table S2). The spent nZVI contained $483.1 \mathrm{mg} / \mathrm{g}$ Fe and $96.6 \mathrm{mg} / \mathrm{g} \mathrm{As}$, and the content of other heavy metals including $\mathrm{Zn}, \mathrm{Cd}, \mathrm{Cu}, \mathrm{Mn}$ and $\mathrm{Cr}$ is listed in Table S3 in the supporting information (SI). The nZVI waste residue was stored at $4{ }^{\circ} \mathrm{C}$.

\subsection{Bacterium strain Pantoea sp. IMH}

IMH was isolated from the As-contaminated soil as reported in our previous study (Wu et al., 2013). IMH can resist up to $150 \mathrm{mM}$ $\mathrm{As}(\mathrm{V})$ and $20 \mathrm{mM} \mathrm{As}(\mathrm{III})$, and can effectively reduce $\mathrm{As}(\mathrm{V})$ with ars operons (Tian and Jing, 2014; Wang et al., 2016; Wu et al., 2013). The specific components of the culture medium for IMH are detailed in the SI. The culture medium used in incubation experiments was diluted to simulate the real environment. The maximum dilution ratio was selected to be four for IMH growth (Fig. S1).

\subsection{Incubation experiments}

IMH was activated in a $30{ }^{\circ} \mathrm{C}$ incubator shaking at $150 \mathrm{rpm}$ for $12 \mathrm{~h}$ (Tian et al., 2015). Then, IMH was inoculated into the culture medium (800 mL) containing $5 \mathrm{~g} \mathrm{~L}^{-1} \mathrm{nZVI}$ sludge. The quantity of IMH inoculation was varied from 5 to $20 \%$ and the optimized inoculation quantity was $5 \%$ as evidenced by high As(III) concentration (Fig. S2).

Triplicate incubation samples and abiotic controls were incubated aerobically in Erlenmeyer flasks sealed with sterilized air- permeable film and shaken at $150 \mathrm{rpm}$ for $36 \mathrm{~h}$ at $30^{\circ} \mathrm{C}$. The control sample was prepared following the same procedure as the incubation sample, except without IMH inoculation.

Each incubation and control sample was monitored periodically to determine the number of living cells and the soluble concentration of $\mathrm{As}(\mathrm{III}), \mathrm{As}(\mathrm{V}), \mathrm{Fe}(\mathrm{II})$, total $\mathrm{Fe}$, anions $\left(\mathrm{SO}_{4}^{2-}, \mathrm{NO}^{3-}, \mathrm{Br}^{-}, \mathrm{Cl}^{-}\right.$, $\left.\mathrm{PO}_{4}^{3-}, \mathrm{F}^{-}\right)$, and other metals $(\mathrm{Cr}, \mathrm{Cu}, \mathrm{Zn}, \mathrm{Mn}, \mathrm{Cd})$. The solids at the end of the incubation were collected by centrifugation at $10,000 \mathrm{~g}$ (Eppendorf 5424, Hamburg, Germany) for 5 min and washed with autoclaved deionized (DI) water three times. The samples were freeze dried for analysis by XAFS and Mössbauer spectroscopy.

\subsection{Aqueous analysis}

The As concentration and speciation were determined by a highperformance liquid chromatography (HPLC) coupled with atomic fluorescence spectrometry (AFS, Haiguang, China). The detection limits were $0.7 \mu \mathrm{g} / \mathrm{L}$ for $\mathrm{As}(\mathrm{III})$ and $1.7 \mu \mathrm{g} / \mathrm{L}$ for $\mathrm{As}(\mathrm{V})$ (Fig. S3). Ferrous iron was quantified using the colorimetric 1, 10phenanthroline method. Total iron and other metal concentrations ( $\mathrm{Zn}, \mathrm{Cu}, \mathrm{Cd}, \mathrm{Cr}, \mathrm{Mn}$ ) were analyzed using inductively coupled plasma optical emission spectrometry (ICP-OES, Perkin Elmer, US). The cell number was examined through the colony counting method. Anions were determined using DX-1100 ion chromatography (Dionex, Sunnyvale, CA) with an AS11-HC Ion Pac column. The detection limits were $32 \mu \mathrm{g} / \mathrm{L}_{\text {for SO }}^{2-}, 14 \mu \mathrm{g} / \mathrm{L}_{4}$ for $\mathrm{Cl}^{-}, 12 \mu \mathrm{g} / \mathrm{L}$ for $\mathrm{NO}^{3-}, 24 \mu \mathrm{g} / \mathrm{L}$ for $\mathrm{Br}^{-}, 19 \mu \mathrm{g} / \mathrm{L}$ for $\mathrm{PO}_{4}^{3-}$ and $13 \mu \mathrm{g} / \mathrm{L}_{\text {for }} \mathrm{F}^{-}$.

\subsection{XAFS analysis}

The solid samples were freeze-dried and deposited onto a strip of Kapton tape for analysis. Micro X-ray fluorescence ( $\mu$-XRF) and $\mu$ $\mathrm{X}$-ray absorption near edge structure ( $\mu$-XANES) spectra were collected at beamline $15 \mathrm{U}$ at Shanghai Synchrotron Radiation Facility (SSRF), China. The beam was focused to measure a spot size of $3.5 \times 3.5 \mu \mathrm{m}^{2}$ by a Kirkpatrick-Baez (KB) mirror system. The $\mu-\mathrm{XRF}$ mapping of the distribution of As and Fe were collected at $14 \mathrm{keV}$. Dwell-time per pixel was adjusted to1.0 s and the step size was $3.5 \mu \mathrm{m}$. As K-edge $\mu$-XANES spectra were collected from the spots of interest in the $\mu$-XRF maps. The spectra were analyzed using linear combination fitting (LCF) with the Athena program in the Demeter computer package (Hu et al., 2015a; Ravel and Newville, 2005).

The As and Fe K-edge XAFS spectra were collected at beamline $14 \mathrm{~W}$ at SSRF. As spectra were acquired from -200 to $800 \mathrm{eV}$ relative to As K-edge $\left(\mathrm{As}^{0}, 11,867 \mathrm{eV}\right)$ with a step size of $0.5 \mathrm{eV}$ at the edge region. The Fe spectra were obtained from -150 to $300 \mathrm{eV}$ relative to the Fe K-edge $\left(\mathrm{Fe}^{0}, 7112 \mathrm{eV}\right)$ with a step size of $0.3 \mathrm{eV}$ at the edge region. The fluorescence signals were collected using aLytle detector positioned at $90^{\circ}$ to the incident beam, and the sample was at a $45^{\circ}$ angle to the detector. Standard reference chemicals, $\mathrm{Na}_{2} \mathrm{HAsO}_{4} \cdot 7 \mathrm{H}_{2} \mathrm{O}, \mathrm{NaAsO}_{2}, \mathrm{AsS}, \mathrm{As}_{2} \mathrm{~S}_{3}, \mathrm{FeS}, \mathrm{FeS}_{2}, \mathrm{Fe}_{3} \mathrm{O}_{4}$, $\mathrm{Fe}_{2} \mathrm{O}_{3}$, goethite, and ferrihydrite were also analyzed. Standard chemicals were sealed between two layers of Kapton tape for the XANES measurement in transmission mode. XANES spectra were analyzed using LCF fitting and EXAFS data were analyzed using standard FEFF shell fitting approach as used in our previous studies and detailed in the SI.

\subsection{Mössbauer analysis}

For ${ }^{57} \mathrm{Fe}$ Mössbauer measurement, the powdered sample (80-100 mesh) was gently pressed into a brass sample holder (16 mm diameter, $1 \mathrm{~mm}$ thick). The sample holder was closed at both ends with iron-free plastic taps. Mössbauer spectra were measured at $293 \mathrm{~K}$ with an Austin Science S-600 Mössbauer 
spectrometry using a $\gamma$-ray source of $1.11 \mathrm{GBq}^{57} \mathrm{Co} / \mathrm{Rh}$. Measured spectra were fitted to Lorentzian line shapes using standard line shape fitting routines. The half-width and peak intensities of the quadruple doublet were constrained as equal. Isomer shifts were expressed with respect to the centroid of the spectrum of metallic iron foil. The software package WinNoroms-for-Igor was used to analyze measured spectra and the rates of all iron speciation were calculated according to peak area.

\subsection{Statistical analysis}

The software IBM SPSS Statistics, version 20.0, was used to perform the statistical analysis. Correlation analysis between two different elements was performed. An independent-sample $t$-test was used to ascertain possible significant differences between the incubated and control samples. Significance was considered when $\mathrm{p}<0.05$.

\section{Results and discussion}

\subsection{Soluble As and Fe speciation}

Dissolved As(III) and As(V) concentrations were monitored by HPLC-AFS during the incubation (Fig. 1a). No methyl As compounds were detected. Notably, $\mathrm{As}(\mathrm{V})$ was almost completely reduced to As(III) by IMH within $30 \mathrm{~h}$, concomitant with the growth of IMH. In line with our previous study (Wu et al., 2013), the rate in $\mathrm{As}(\mathrm{V})$ reduction was slower in the first $10 \mathrm{~h}\left(0.45 \mathrm{mg} \mathrm{L}^{-1} \cdot \mathrm{h}^{-1}\right)$, then increased rapidly $\left(3.21 \mathrm{mg} \mathrm{L}^{-1} \cdot \mathrm{h}^{-1}\right)$ when IMH grew in the logarithmic phase, and finally decreased $\left(0.97 \mathrm{mg} \mathrm{L}^{-1} \cdot \mathrm{h}^{-1}\right)$ at IMH's stationary phase (Fig. S4). This As(V) reduction variation is in a good agreement with a previous study using an arsC carrier, Pseudomonas sp. PAHAs-1 (Feng et al., 2014).

Almost no difference was observed in total dissolved As in control and inoculated samples (Fig. 1a and b), suggesting that IMH had a negligible contribution to the As release from nZVI. In fact, the total dissolved As concentration was positively correlated with dissolved $\mathrm{Fe}$ in control $(p=0.032)$ and inoculated $(p=0.042)$ samples (Fig. 1c), in line with previous studies (LeMonte et al., 2017; Tian et al., 2015). Furthermore, dissolved $\operatorname{As}(\mathrm{V})(p=0.012)$ and As(III) $(p=0.015)$ were significantly correlated with dissolved Fe in inoculated samples, whereas such a correction was only observed for $\operatorname{As}(\mathrm{V})(p=0.017)$, not for $\operatorname{As}(\mathrm{III})(p=0.059)$ in control samples (Fig. 1d and e).

The growth of IMH was also monitored during the incubation (Fig. 1a), and the number of living cells was significantly negative correlated with $\mathrm{As}(\mathrm{V})(p=0.003)$ and positive correlated with As(III) $(p=0.002)$, but not with total dissolved As $(p=0.079)$ (Fig. 1f). The results indicate that IMH plays a decisive role in soluble As speciation, but has no impact on the As release. We therefore speculated that IMH should entirely prefer reduce the dissolved $\mathrm{As}(\mathrm{V})$ rather than the solid-bound $\mathrm{As}(\mathrm{V})$. This hypothesis motivates our following study on the As speciation in solids.

Decrease in soluble Fe(III) and Fe(II) concentrations followed the second-order kinetics in both inoculated and control samples (Fig. 1b and Fig. S5). Interestingly, Fe(III) concentration was higher than $\mathrm{Fe}(\mathrm{II})$, suggesting almost fully oxidation of nZVI. Fe(III) may form soluble complexes with various organic molecules in the culture media or secreted by IMH (Park and Dempsey, 2005; Yang et al., 2015), resulting in an elevated Fe(III) concentration (Lofts et al., 2008; Pham et al., 2006). During the incubation, $\mathrm{pH}$ remained in the range 6.7-7.3 (Fig. S6), which only had minor effect on the change in Fe concentrations. The dissolved Fe concentration in this study was similar to that during the nZVI aging in a previous report (Calderon and Fullana, 2015).
No significant difference was observed between inoculated and control samples for both $\mathrm{Fe}(\mathrm{III})(p=0.525)$ and $\mathrm{Fe}(\mathrm{II})(p=0.848)$, implying that IMH facilitated neither Fe(III) precipitation/dissolution nor its reduction. Interestingly, decrease in dissolved As concentration ( $9 \%$ for the control and $12 \%$ for the inoculated sample) was not proportional to that of Fe (61\% for the control and $62 \%$ for the inoculated sample) (Fig. 1b), indicating that the fresh precipitated iron oxides did not uptake As by the same ratio as in the initial nZVI residues. This observation differs from a previous study which shows that the As retention would be enhanced during the transformation of iron oxides to a secondary iron phase such as magnetite (Islam et al., 2005; Kocar et al., 2010). Such a difference might be attributed to the As uptake capability by the in situ formed secondary iron phase, highlighting the importance of $\mathrm{Fe}$ speciation analysis in solids (LeMonte et al., 2017).

In contrast to As and $\mathrm{Fe}$, dissolved concentrations of other heavy metals $(\mathrm{Zn}, \mathrm{Cu}$ and $\mathrm{Cd})$ and anions $\left(\mathrm{Cl}^{-}\right.$and $\left.\mathrm{SO}_{4}^{2-}\right)$ were low and remained constant in both control and incubation samples (Fig. S7), implying that the environmental behaviors of these ions are not affected by the activity of IMH.

\subsection{Speciation and association of As and Fe in solids}

The As K-edge XANES analysis was used to determine the As speciation in solids, and experimental data and LCF results are shown in Fig. 2 and Table S4. The percentage of As(III) in the raw nZVI residue (14.5\%) reduced to $3.1 \%$ in the control sample. This decrease in the $\mathrm{As}(\mathrm{III})$ percentage was ascribed to the fact that adsorbed As(III) may be oxidized to $\mathrm{As}(\mathrm{V})$ by dissolved oxygen (Fig. 1a).

Incubation with IMH slightly increased the As(III) percentage from $15 \%$ in nZVI residue to $19 \%$, probably due to re-adsorption of dissolved As(III) (Tufano et al., 2008). Compared with the $100 \%$ $\mathrm{As}(\mathrm{III})$ in the soluble phase due to $\mathrm{As}(\mathrm{V})$ bio-reduction (Fig. 1), in situ $\mathrm{As}(\mathrm{V})$ reduction on solid was inhibited, revealing that IMH prefers to reduce dissolved $\mathrm{As}(\mathrm{V})$ rather than adsorbed $\mathrm{As}(\mathrm{V})$. This conclusion is understandable because the cytoplasmic ars $\mathrm{C}$ reductase in IMH only reduces the $\mathrm{As}(\mathrm{V})$ transported inside the cells, not the solid-bound As(V) outside the cells (Oremland and Stolz, 2005; Wang et al., 2016). Similarly, another arsC gene container, Clostridium sp. $\mathrm{CN} 8$, is not able to reduce $\mathrm{As}(\mathrm{V})$ adsorbed on ferrihydrite (Langner and Inskeep, 2000). However, another research found the occurrence of $\mathrm{As}(\mathrm{III})$ on the initially $\mathrm{As}(\mathrm{V})$ occupied goethite surface in the presence of two arsC carriers, suggesting that the arsC carriers may directly reduce $\mathrm{As}(\mathrm{V})$ adsorbed on goethite (Guo et al., 2015). Nevertheless, this argument may not be enough to deduce a direct $\mathrm{As}(\mathrm{V})$ bio-reduction on surfaces because the possibility of re-adsorption of soluble $\mathrm{As}(\mathrm{III})$ on goethite can not be excluded (Wang et al., 2014). Fig. 3 shows the spatial distribution of As and Fe in solids determined using $\mu$-XRF and the corresponding As $\mu$ XANES spectra at five different spots. The As distribution was linearly correlated with that of Fe in inoculated $(R=0.97)$ and control $(\mathrm{R}=0.95)$ samples (Figs. S8-S9). The distribution of all other metals including $\mathrm{Zn}, \mathrm{Cd}, \mathrm{Cr}$, Mn, and $\mathrm{Cu}$ was also linearly correlated with that of Fe (Figs. S8-S9), confirming that nZVI is an effective metal scavenger.

Five As $\mu$-XANES spectra were collected at different Fe fluorescence intensity spots, and their LCF results clearly reveal the inhomogeneity heterogeneity and complexity of the inoculated and control samples (Fig. 3). The extent of As reduction, as indicated by the percentage of $\mathrm{As}$ (III) on solids, was not a function of Fe content. For example, almost all As was in $\mathrm{As}(\mathrm{V})$ form on spots 1 and 2 in the control sample with different Fe contents as evidenced by the arbitrary Fe fluorescence intensity, 33,364 and 89,036, respectively. The IMH incubation did not change this random association of As 

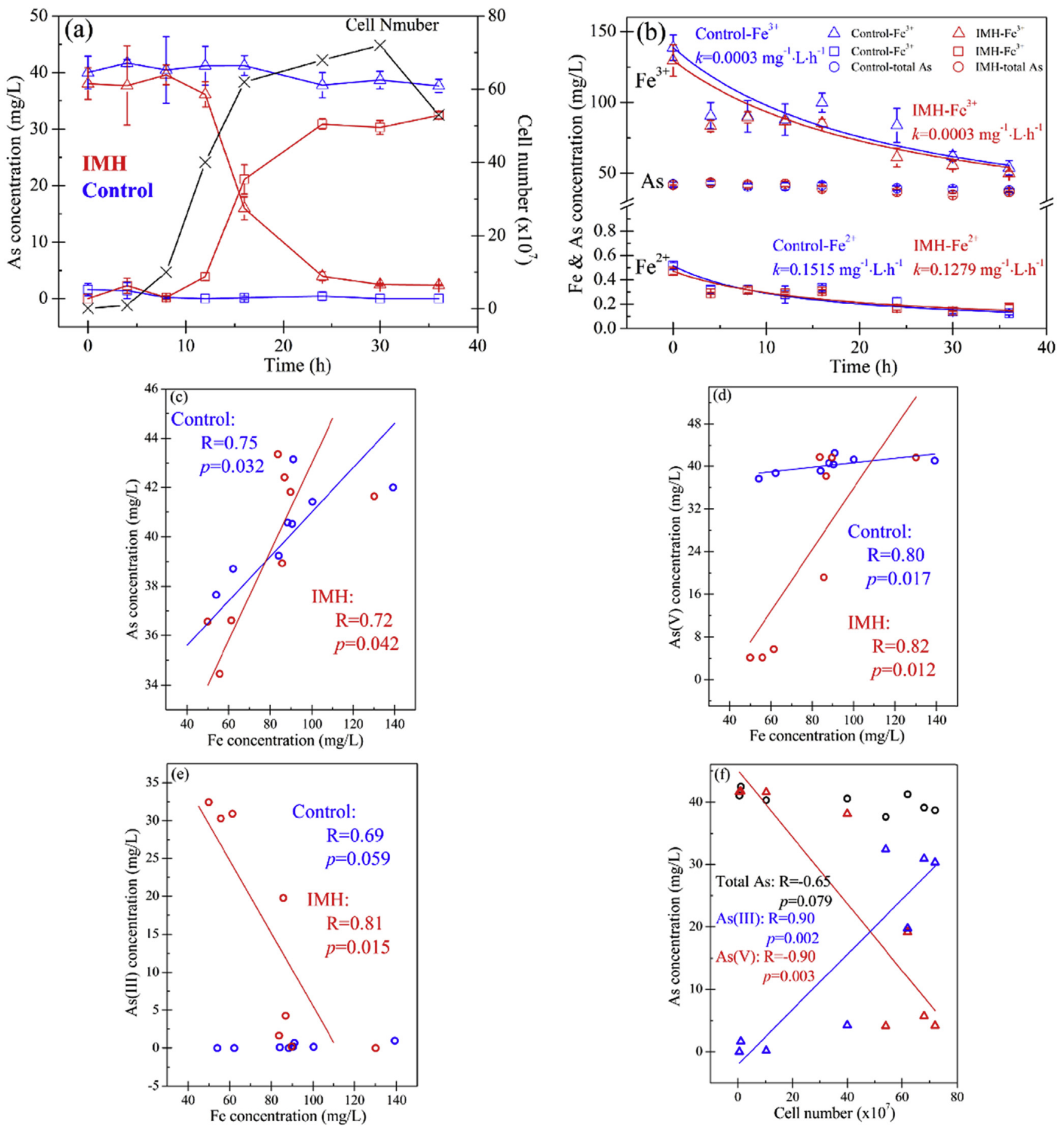

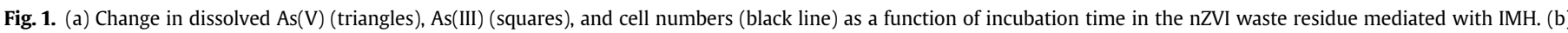

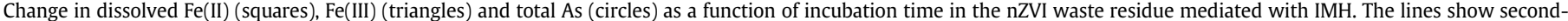

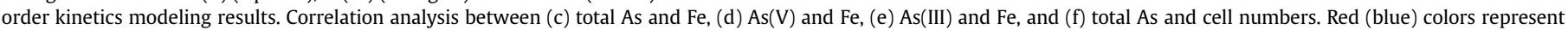

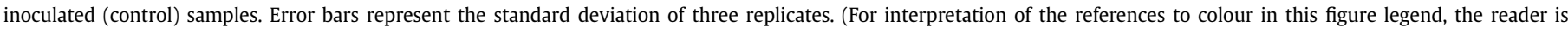
referred to the web version of this article.)

speciation and Fe content. Spots 3-5 in the incubation sample with the Fe intensity at 79,291, 85,287, and 19,370 contained $30 \%, 1 \%$, and zero As(III), respectively.

EXAFS analysis was used to investigate the change in As coordination environments mediated by IMH, and the results are shown in Fig. 4 and Table S6. The first FT peak in the inoculated (control) sample was resulted from 3.3 (3.9) oxygen atoms at 1.67 (1.69) $\AA$ corresponding to $\mathrm{As}(\mathrm{V})-\mathrm{O}$ single scattering $(\mathrm{SS})$ path, and $0.5(0.1)$ oxygen atoms at 1.79 (1.82) Å corresponding to As(III)-O SS path (Hu et al., 2015a; Ona-Nguema et al., 2005). According to the As-O atomic distance and coordination number, approximately $82 \%$ (97\%) As(V) and 17\% (3\%) As(III) existed in the inoculated (control) sample, consistent with the XANES analysis (Fig. 2).

Multiple scattering (MS) that contained $12 \mathrm{As}(\mathrm{V})-\mathrm{O}-\mathrm{O}$ paths and $6 \mathrm{As}(\mathrm{III})-\mathrm{O}-\mathrm{O}$ paths was considered to improve the fit in the 2.8-3.3 A region (Sherman and Randall, 2003). Including MS 

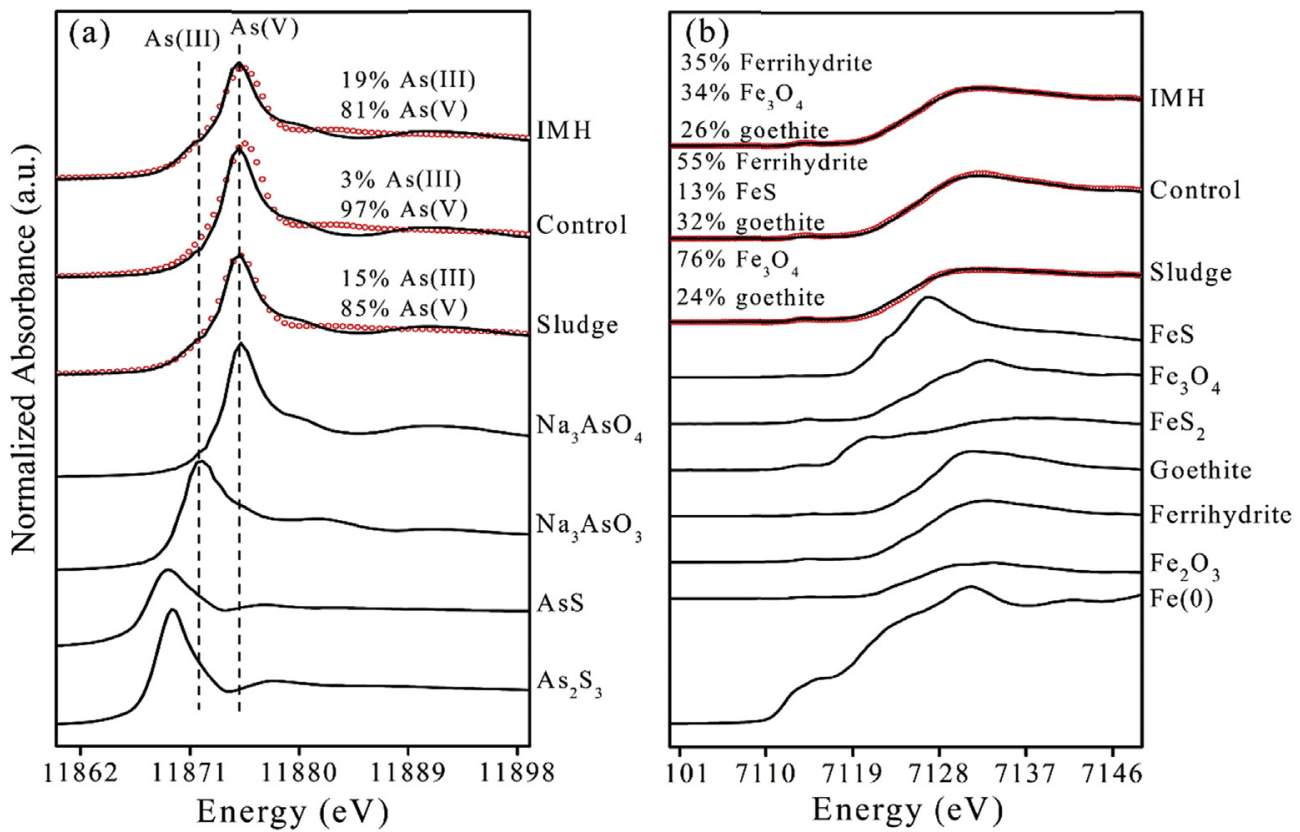

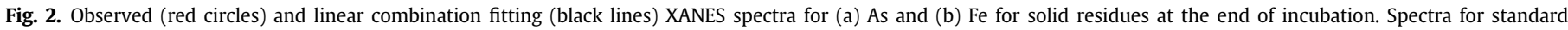
references are also shown for comparison. (For interpretation of the references to colour in this figure legend, the reader is referred to the web version of this article.)

\section{(I) Control}
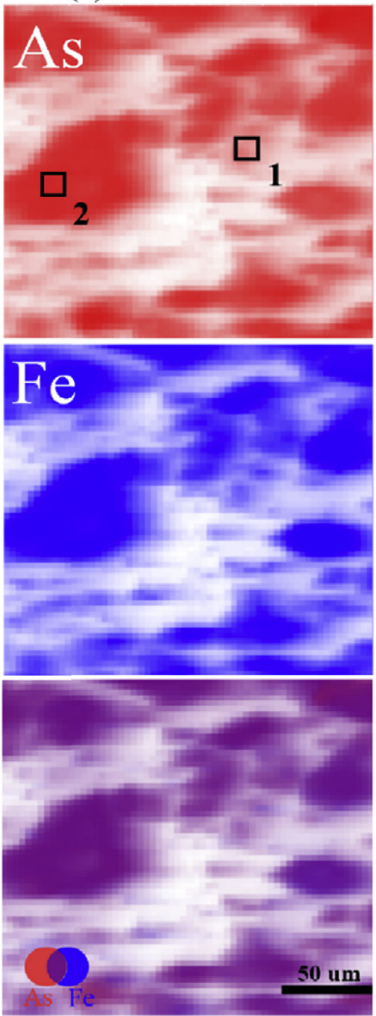

(II) $\mathrm{IMH}$
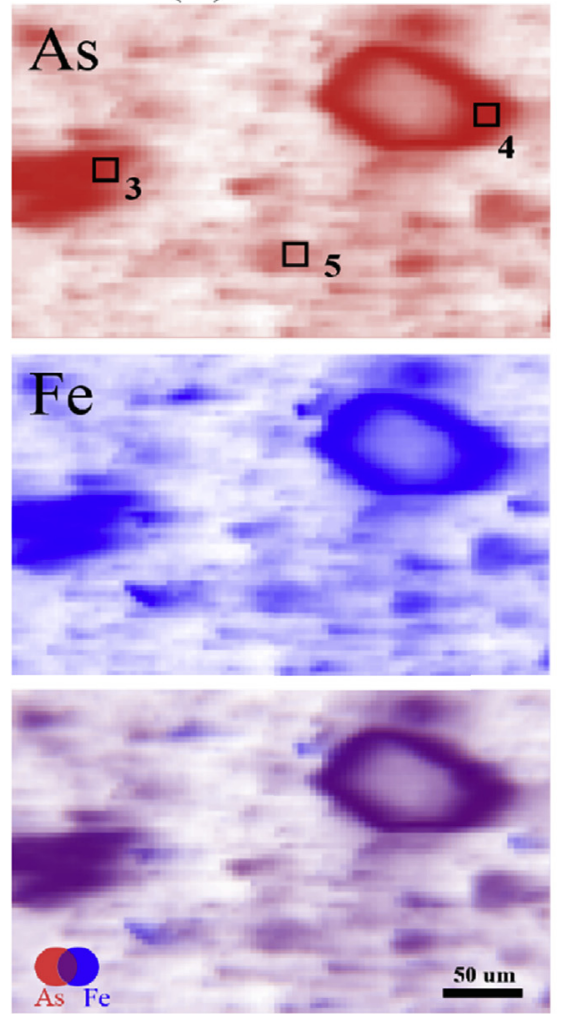

(III)

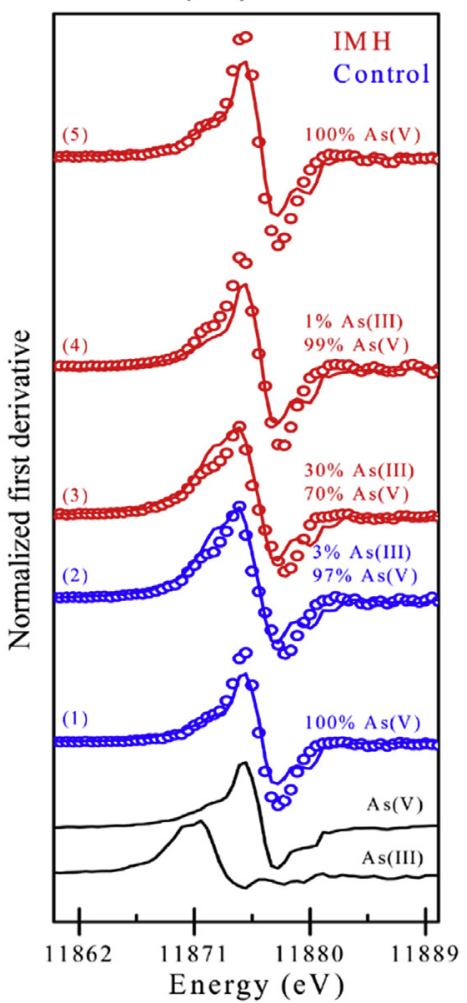

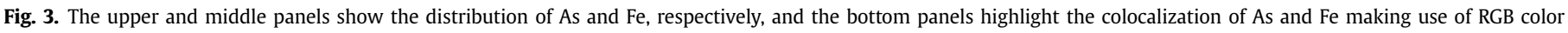

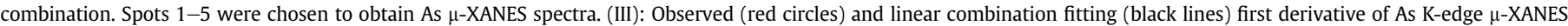

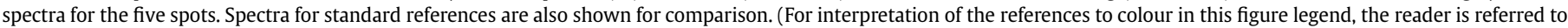
the web version of this article.)

improved the fitting quality without adding extra variables because the MS parameters were constrained (Hu et al., 2015b).

The second peak in the inoculated (control) sample was attributed to As-Fe bonding at 3.36 (3.33) A with 1.9 (1.9) Fe. The As-Fe distance of 3.3-3.4 A corresponded to bidentate binuclear corner-sharing As complex on the $\mathrm{Fe}$ (hydr)oxides surface 

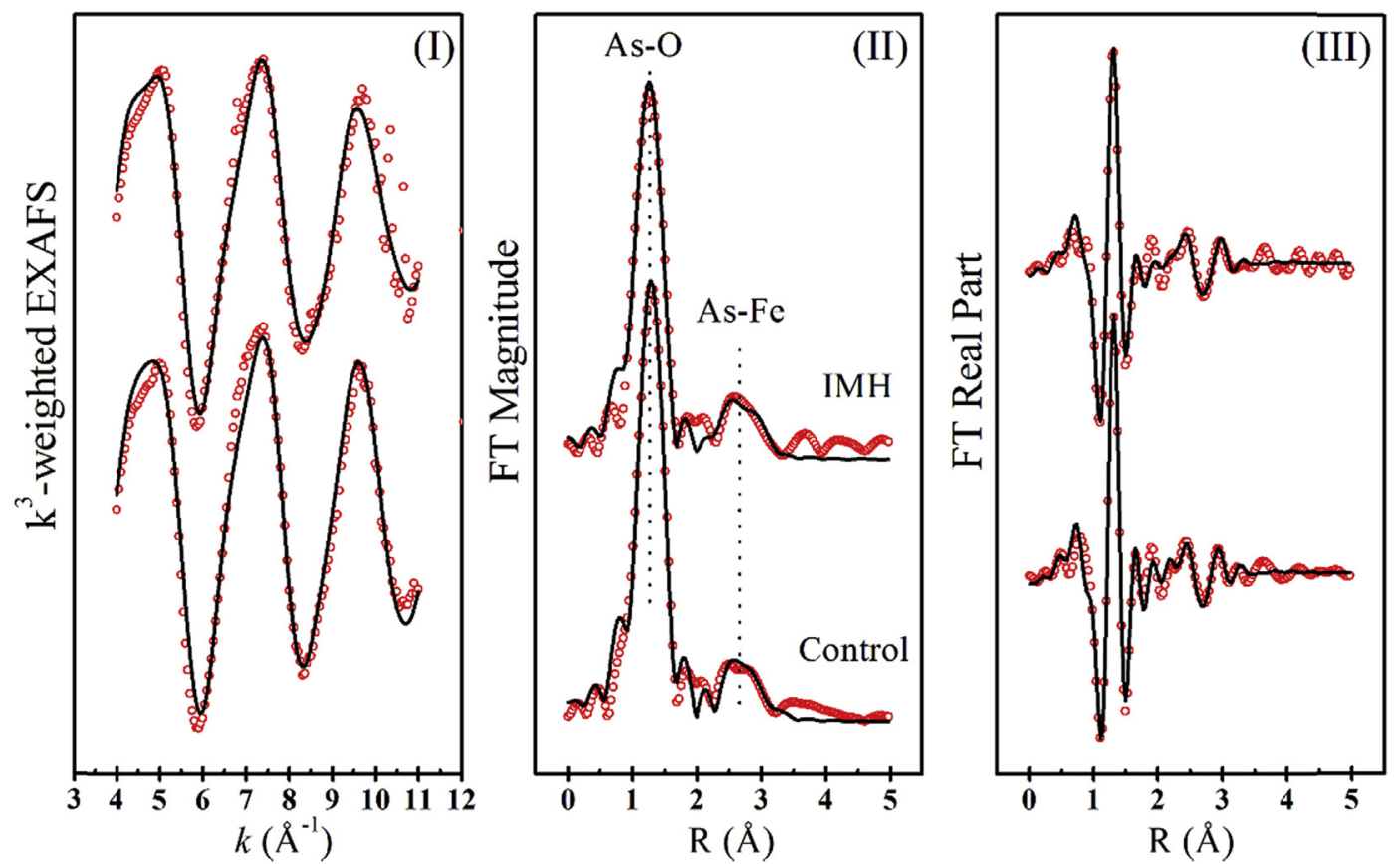

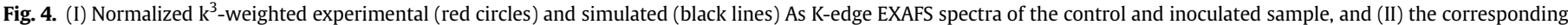

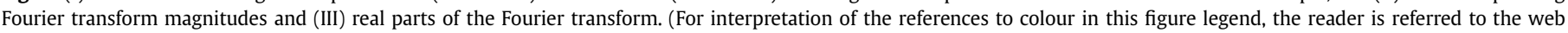
version of this article.)

(Sherman and Randall, 2003). Clearly, no significant As-Fe local coordination difference was resolved between the inoculated and control samples. Had $\mathrm{As}(\mathrm{V})$ been reduced in situ on iron oxide surfaces by IMH, the As local coordination environment, as well as the oxidation state of As resolved with XANES analysis (Table S4), should change accordingly. However, this hypothesized surface configuration change was not supported by our EXAFS analysis, confirming that arsC carriers reduce dissolved $\mathrm{As}(\mathrm{V})$ but not adsorbed $\mathrm{As}(\mathrm{V})$.

The evidences suggest that the release from nZVI residue is a prerequisite for $\mathrm{As}(\mathrm{V})$ reduction by IMH. Because IMH did not reduce $\mathrm{Fe}(\mathrm{III})$ as evidenced by the negligible $\mathrm{Fe}(\mathrm{II})$ concentration in the inoculated sample (Fig. 1b), IMH cannot facilitate As(V) release in the same magnitude as those dissimilatory $\mathrm{Fe}(\mathrm{III})$ and $\mathrm{As}(\mathrm{V})$ reducers such as Shewanella putrefaciens 200 (Jiang et al., 2013). However, this does not necessarily prevent IMH from indirectly influencing the formation of secondary Fe minerals which play a role in the fate of As. Then, the impact of IMH on the change in Fe speciation during the incubation motivated our following study.

\subsection{Fe speciation in solids}

To examine the effect of IMH on Fe speciation in solids, XANES analysis was employed. The Fe K-edge XANES spectra imply that the inoculated sample contained predominantly $\mathrm{Fe}^{3+}$ (Fig. 2 and Table S6). The K-edge XANES analysis indicates that $\mathrm{Fe}_{3} \mathrm{O}_{4}(76 \%)$ and goethite $(24 \%)$ were the primary Fe-containing minerals in the raw sludge. Elemental iron was not detected, probably due to the oxidation of nZVI during the long-term exposure to oxygenated environments. In the abiotic control, ferrihydrite (55\%), goethite (32\%), and ferrous containing phase (13\%) were the primary $\mathrm{Fe}$ components, but no $\mathrm{Fe}_{3} \mathrm{O}_{4}$ was detected. The result indicates that when the nZVI sludge was in contact with water, magnetite would be oxidized and transformed to ferrihydrite, consistent with the evolution of nZVI (Liu et al., 2017). As(V) was released and its concentration remained unchanged at approximately $40 \mathrm{mg} / \mathrm{L}$
(Fig. 1a). In the inoculated sample, the $\mathrm{Fe}_{3} \mathrm{O}_{4}$ content was reduced from $76 \%$ in the raw sludge to $34 \%$, whereas ferrihydrite (35\%) was detected (Fig. 2-b). Such a transition from primary iron oxide to the secondary phase was generally proposed to contribute the As reuptake and immobilization by previous studies (Islam et al., 2005). In contrast, our study shows that As was not immobilized during the formation of ferrihydrite, the secondary iron phase (Fig. 1). Actually, magnetite, the primary phase of iron oxide in our study, exhibited higher As adsorption capacity than ferrihydrite (Wang et al., 2014). Integrating results from this and previous studies indicate that the re-uptake of released As can be either enhanced or weakened, depending on the difference in the As affinity between the primary and secondary iron phases.

IMH slowed down the nZVI aging process as evidenced by the $34 \% \mathrm{Fe}_{3} \mathrm{O}_{4}$ in the inoculated sample compared with zero $\mathrm{Fe}_{3} \mathrm{O}_{4}$ in the control (Fig. 2-b). In fact, the nZVI aging process was influenced by microorganisms through electrons transfer (Kato et al., 2010) or bacterial metabolites (Newman and Kolter, 2000; Xie et al., 2017). $\mathrm{IMH}$ reduced $\mathrm{As}(\mathrm{V})$ through $\operatorname{ars} C$ genes in the cell body (Wang et al., 2016) without electron transport with nZVI (Wang et al., 2016), bacterial metabolites may directly or indirectly slow down the aging of nZVI.

To further explore the Fe phase in the presence of IMH, Mössbauer spectroscopy was used to provide insights into the valence state and coordination of $\mathrm{Fe}$ atoms. The ${ }^{57} \mathrm{Fe}$ Mössbauer spectra in Fig. 5 resolve several overlapping doublets and sextets, and the fitting results are listed in Table S8 including isomer shift (IS), quadruple splitting (QS), hyperfine field (Hi) and half-width (HW). In the control sample (Fig. 5a), the doublet (green line) with IS $=0.23 \mathrm{~mm} / \mathrm{s}$ and $\mathrm{QS}=0.64 \mathrm{~mm} / \mathrm{s}$ was ascribed to the paramagnetic ferric iron (para- $\mathrm{Fe}^{3+}$ ), and two magnetic sextets were associated with the magnetic-Fe corresponding to a tetrahe-

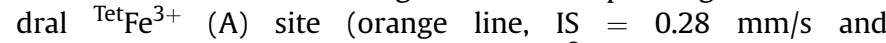
$\mathrm{QS}=-0.009 \mathrm{~mm} / \mathrm{s}$ ) and an octahedral ${ }^{\mathrm{Oct}} \mathrm{Fe}(\mathrm{B})$ site (blue line, IS $=0.66 \mathrm{~mm} / \mathrm{s}$ and $\mathrm{QS}=0.013 \mathrm{~mm} / \mathrm{s}$ ) (Gorski and Scherer, 2010). Site $\mathrm{B}$ can also be written as ${ }^{\mathrm{Oct}} \mathrm{Fe}^{2.5}$ as a result of fast electron 

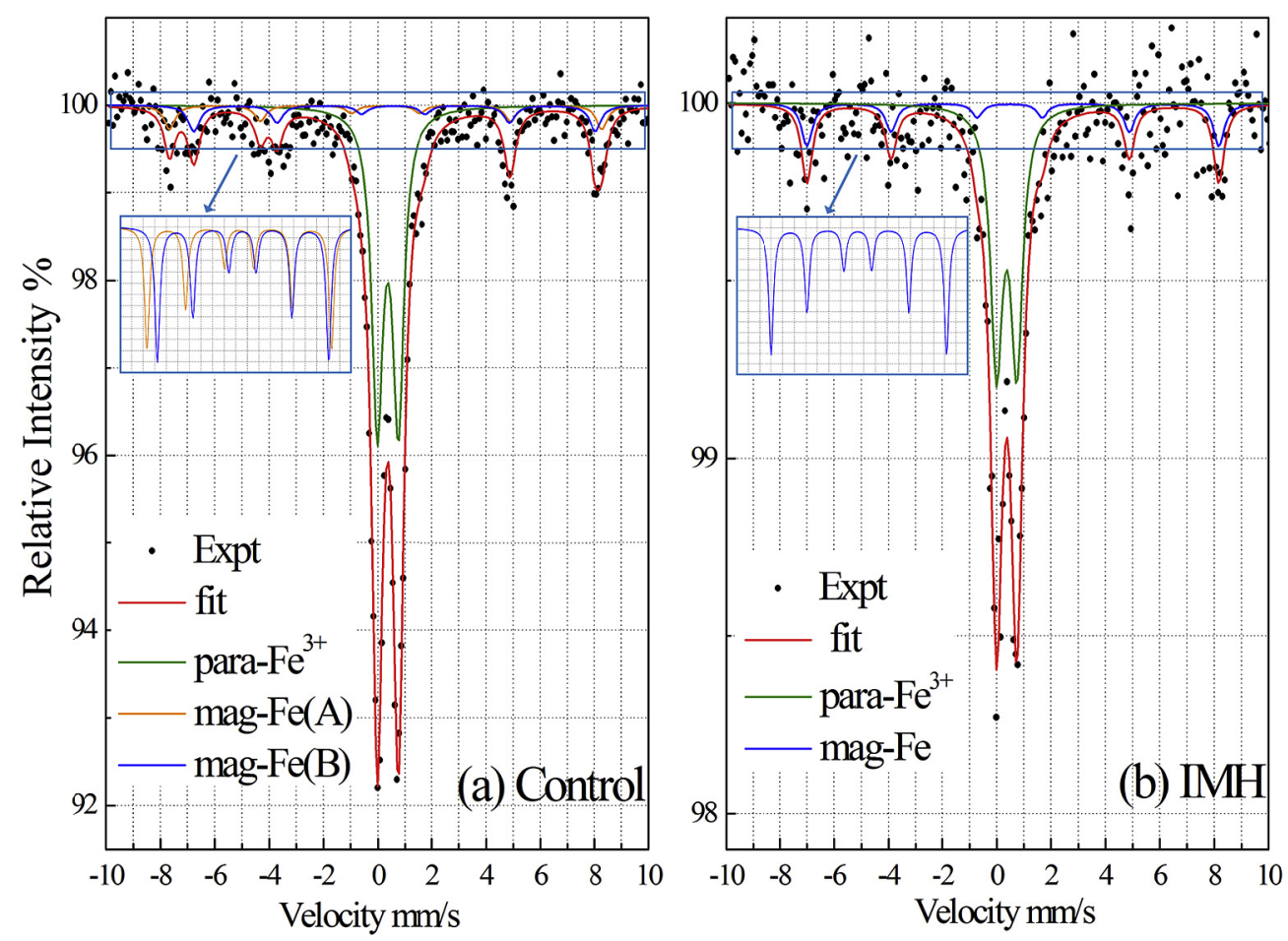

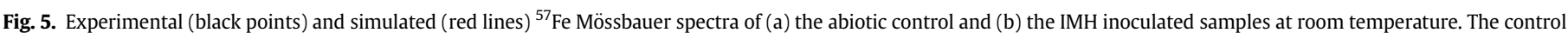

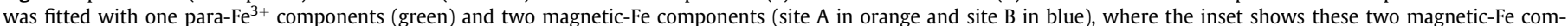

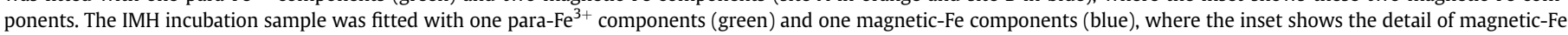
component. (For interpretation of the references to colour in this figure legend, the reader is referred to the web version of this article.)

hopping between ${ }^{\text {Oct }} \mathrm{Fe}^{2+}$ and ${ }^{\text {Oct }} \mathrm{Fe}^{3+}$ (Skoropata et al., 2014). In the inoculated sample (Fig. 5b), the doublet (green line) with IS $=0.36 \mathrm{~mm} / \mathrm{s}$ and $\mathrm{QS}=0.75 \mathrm{~mm} / \mathrm{s}$ was due to para- $\mathrm{Fe}^{3+}$, similar to the para- $\mathrm{Fe}^{3+}$ in the control. There was only one sextet (blue line, IS $=0.53 \mathrm{~mm} / \mathrm{s}$ and $\mathrm{QS}=0.104 \mathrm{~mm} / \mathrm{s}$ ) associated with magnetic$\mathrm{Fe}^{3+}$. Mössbauer results reveal that both control and inoculated samples contained predominantly $\mathrm{Fe}^{3+}$. In agreement with XANES results, Mössbauer analysis shows that IMH had little impact on the valence state of iron.

The Mössbauer results as listed in Table S8 provided insights into the difference in magnetic-Fe between the control and inoculated samples. The IS $(0.53 \mathrm{~mm} / \mathrm{s})$ and $\mathrm{Hi}(47.05 \mathrm{~T})$ values of the magnetite sextet in the inoculated sample were between values in the control for site A (IS $=0.28 \mathrm{~mm} / \mathrm{s}, \mathrm{Hi}=49.28 \mathrm{~T}$ ) and site B (IS $=0.66 \mathrm{~mm} / \mathrm{s}, \mathrm{Hi}=46.20 \mathrm{~T}$ ). This observation suggests that the local structure of magnetic- $\mathrm{Fe}^{3+}$ in the inoculated sample was in a state between sites A $\left({ }^{\mathrm{Tet}} \mathrm{Fe}^{3+}\right.$ ) and B $\left({ }^{\mathrm{Oct}} \mathrm{Fe}^{2.5}\right.$ ) (Byrne et al., 2015; Reynolds et al., 2014). Actually, the absolute QS value in the inoculated sample was much higher than that in sites A and B, suggesting a more distorted polyhedron coordination (Skoropata et al., 2014). The analysis shows that although IMH did not change the valence state of $\mathrm{Fe}$, it did influence the local coordination of $\mathrm{Fe}$ atoms, most probably through its bio-generated organic molecules (Halama et al., 2016). Then, our next concern is whether this Fe coordination change has an impact on As release?

Interestingly, the distortion of $\mathrm{Fe}$ polyhedron coordination mediated by IMH did not change the As adsorption capacity as evidenced by the same dissolved As concentration in the inoculated and control sample. Nevertheless, the percentage on adsorbed $\mathrm{As}(\mathrm{III})$ in the inoculated sample (19\%) was higher than that in the control (3\%, Fig. 2a). This is understandable because the bioreduced As(III) could be re-adsorbed on the solid surface (Tufano et al., 2008), with the same bidentate binuclear surface configuration as $\mathrm{As}(\mathrm{V})$ (Fig. 4).

\section{Conclusions}

nZVI has been widely used to mitigate As and other heavy metals from wastewater and contaminated soil, and consequently the spent nZVI residue is of high environmental concern. Our results highlight the risk of spent nZVI that may have been underappreciated previously. Although As mobility is considered negligible under aerobic conditions because most $\mathrm{As}(\mathrm{V})$ and $\mathrm{Fe}(\mathrm{III})$ reducers are of no effect, arsC containers such as strain IMH can readily reduce dissolved $\mathrm{As}(\mathrm{V})$ to more toxic $\mathrm{As}(\mathrm{III})$ aerobically. Our study indicates that $\mathrm{As}(\mathrm{V})$-reducing bacteria with ars $\mathrm{C}$ genes play an important role in the biotransformation and mobility of As in the aerobic environment.

It is widely accepted that ars $\mathrm{C}$ gene carriers alone make no difference on the speciation and phase of iron minerals. However, the bacterial activity slow down the nZVI aging process and distort the Fe local coordination which may have an impact on the fate and transport of attached pollutants.

Previous studies suggest that As retention may be enhanced due to As re-uptake by in situ bio-transformed Fe secondary phase. Our results reveal that the As retention is dependent on the relative As affinity between the primary and secondary iron minerals. Therefore, the consequence of secondary Fe mineral formation to As immobilization should be evaluated on a case-by-case basis.

\section{Acknowledgements}

We acknowledge the financial support of the National Basic Research Program of China (2015CB932003, 2014CB441102), the 


\section{Strategic Priority Research Program of the Chinese Academy of Sciences (XDB14020201), the National Natural Science Foundation of China (41373123, 41425016, 21321004).}

\section{Appendix A. Supplementary data}

Details of Microbial Incubation; the second order kinetics model; dissolved heavy metals and anions; $\mu$-XRF maps of other heavy metals; Fe L-edge XANES and STXM analysis; analytical procedure; and additional figures. Supporting figures and tables referenced in the text are also included.

Supplementary data related to this article can be found at http:// dx.doi.org/10.1016/j.envpol.2017.07.074.

\section{References}

Bruton, T.A., Pycke, B.F.G., Halden, R.U., 2015. Effect of nanoscale zero-valent iron treatment on biological reductive dechlorination: a review of current understanding and research needs. Crit. Rev. Env. Sci. Tec. 45 (11), 1148-1175.

Byrne, J.M., Klueglein, N., Pearce, C., Rosso, K.M., Appel, E., Kappler, A., 2015. Redox cycling of $\mathrm{Fe}(\mathrm{II})$ and $\mathrm{Fe}(\mathrm{III})$ in magnetite by Fe-metabolizing bacteria. Science 347 (6229), 1473-1476.

Calderon, B., Fullana, A., 2015. Heavy metal release due to aging effect during zero valent iron nanoparticles remediation. Water Res. 83, 1-9.

Cao, M., Ye, Y., Chen, J., Lu, X., 2016. Remediation of arsenic contaminated soil by coupling oxalate washing with subsequent ZVI/Air treatment. Chemosphere 144, 1313-1318.

Cohen, S.M., Chowdhury, A., Arnold, L.L., 2016. Inorganic arsenic: a non-genotoxic carcinogen. J. Environ. Sci. 49, 28-37.

Feng, T., Lin, H., Tang, J., Feng, Y., 2014. Characterization of polycyclic aromatic hydrocarbons degradation and arsenate reduction by a versatile Pseudomonas isolate. Int. Biodeterior. Biodegr. 90, 79-87.

Gil-Diaz, M., Alonso, J., Rodriguez-Valdes, E., Pinilla, P., Carmen Lobo, M., 2014. Reducing the mobility of arsenic in brownfield soil using stabilised zero-valent iron nanoparticles. J. Environ. Sci. Heal A 49 (12), 1361-1369.

Gorski, C.A., Scherer, M.M., 2010. Determination of nanoparticulate magnetite stoichiometry by Mossbauer spectroscopy, acidic dissolution, and powder X-ray diffraction: a critical review. Am. Mineral. 95 (7), 1017-1026.

Guo, H.M., Liu, Z.Y., Ding, S.S., Hao, C.B., Xiu, W., Hou, W.G., 2015. Arsenate reduction and mobilization in the presence of indigenous aerobic bacteria obtained from high arsenic aquifers of the Hetao basin, Inner Mongolia. Environ. Pollut. 203, 50-59.

Halama, M., Swanner, E.D., Konhauser, K.O., Kappler, A., 2016. Evaluation of siderite and magnetite formation in BIFs by pressure-temperature experiments of Fe(III) minerals and microbial biomass. Earth Planet S. C. Lett. 450, 243-253.

Hu, S., Shi, Q.T., Jing, C.Y., 2015a. Groundwater arsenic adsorption on granular TiO2: integrating atomic structure, filtration, and health impact. Environ. Sci. Technol. 49 (16), 9707-9713.

Hu, S., Yan, L., Chan, T.S., Jing, C.Y., 2015b. Molecular insights into ternary surface complexation of arsenite and cadmium on $\mathrm{TiO}_{2}$. Environ. Sci. Technol. 49 (10), 5973-5979.

Islam, F.S., Pederick, R.L., Gault, A.G., Adams, L.K., Polya, D.A., Charnock, J.M., Lloyd, J.R., 2005. Interactions between the Fe(III)-reducing bacterium Geobacter sulfurreducens and arsenate, and capture of the metalloid by biogenic Fe(II). Appl. Environ. Microbiol. 71 (12), 8642-8648.

Jiang, S., Lee, J.-H., Kim, D., Kanaly, R.A., Kim, M.-G., Hur, H.-G., 2013. Differential arsenic mobilization from as-bearing ferrihydrite by iron-respiring Shewanella strains with different arsenic-reducing activities. Environ. Sci. Technol. 47 (15), $8616-8623$.

Kato, S., Nakamura, R., Kai, F., Watanabe, K., Hashimoto, K., 2010. Respiratory interactions of soil bacteria with (semi)conductive iron-oxide minerals. Environ. Microbiol. 12 (12), 3114-3123.

Kim, H., Hong, H.J., Jung, J., Kim, S.H., Yang, J.W., 2010. Degradation of trichloroethylene (TCE) by nanoscale zero-valent iron (nZVI) immobilized in alginate bead. J. Hazard. Mater. 176 (1-3), 1038-1043.

Kocar, B.D., Borch, T., Fendorf, S., 2010. Arsenic repartitioning during biogenic sulfidization and transformation of ferrihydrite. Geochim. Cosmochim. Ac. 74 (3), 980-994.

Langner, H.W., Inskeep, W.P., 2000. Microbial reduction of arsenate in the presence of ferrihydrite. Environ. Sci. Technol. 34 (15), 3131-3136.

LeMonte, J.J., Stuckey, J.W., Sanchez, J.Z., Tappero, R., Rinklebe, J., Sparks, D.L., 2017. Sea level rise induced arsenic release from historically contaminated coastal soils. Environ. Sci. Technol. 51 (11), 5913-5922.

Li, S., Wang, W., Liang, F., Zhang, W.-X., 2017. Heavy metal removal using nanoscale zero-valent iron (nZVI): theory and application. J. Hazard. Mater. 322, 163-171.

Liu, A., Liu, J., Han, J., Zhang, W.-X., 2017. Evolution of nanoscale zero-valent iron (nZVI) in water: microscopic and spectroscopic evidence on the formation of nano- and micro-structured iron oxides. J. Hazard. Mater. 322, 129-135.
Lofts, S., Tipping, E., Hamilton-Taylor, J., 2008. The chemical speciation of Fe(III) in freshwaters. Aquat, Geochem 14 (4), 337-358.

Mak, M.S.H., Rao, P., Lo, I.M.C., 2011. Zero-valent iron and iron oxide-coated sand as a combination for removal of co-present chromate and arsenate from groundwater with humic acid. Environ. Pollut. 159 (2), 377-382.

Meng, M., Sun, W.Q., Geelhaar, L.A., Kumar, G., Patel, A.R., Payne, G.F., Speedie, M.K., Stacy, J.R., 1995. Denitration of glycerol trinitrate by resting cells and cellextracts of bacillus-thuringiensis cereus and enterobacter-agglomerans. Appl. Environ. Microbiol. 61 (7), 2548-2553.

Mumford, A.C., Barringer, J.L., Benzel, W.M., Reilly, P.A., Young, L.Y., 2012. Microbial transformations of arsenic: mobilization from glauconitic sediments to water Water Res. 46 (9), 2859-2868.

Murphy, J.N., Saltikov, C.W., 2009. The ArsR repressor mediates arsenite-dependent regulation of arsenate respiration and detoxification operons of Shewanella sp strain ANA-3. J. Bacteriol. 191 (21), 6722-6731.

Newman, D.K., Kolter, R., 2000. A role for excreted quinones in extracellular electron transfer. Nature 405 (6782), 94-97.

Ona-Nguema, G., Morin, G., Juillot, F., Calas, G., Brown, G.E., 2005. EXAFS analysis of arsenite adsorption onto two-line ferrihydrite, hematite, goethite, and lepidocrocite. Environ. Sci. Technol. 39 (23), 9147-9155.

Oremland, R.S., Stolz, J.F., 2005. Arsenic, microbes and contaminated aquifers Trends Microbiol. 13 (2), 45-49.

Park, B., Dempsey, B.A., 2005. Heterogeneous oxidation of Fe(II) on ferric oxide at neutral $\mathrm{pH}$ and a low partial pressure of $\mathrm{O}_{2}$. Environ. Sci. Technol. 39 (17), 6494-6500.

Pham, A.N., Rose, A.L., Feitz, A.J., Waite, T.D., 2006. Kinetics of Fe(III) precipitation in aqueous solutions at pH 6.0-9.5 and 25 degrees C. Geochim. Cosmochim. Ac. 70 (3), 640-650.

Ravel, B., Newville, M., 2005. Athena, Artemis, Hephaestus: data analysis for X-ray absorption spectroscopy using IFEFFIT. J. Synchrotron. Radiat. 12, 537-541.

Reynolds, R.L., Cattle, S.R., Moskowitz, B.M., Goldstein, H.L., Yauk, K., Flagg, C.B., Berquo, T.S., Kokaly, R.F., Morman, S., Breit, G.N., 2014. Iron oxide minerals in dust of the Red Dawn event in eastern Australia. September 2009 Aeolian Res. $15,1-13$.

Sherman, D.M., Randall, S.R., 2003. Surface complexation of arsenic(V) to iron(III) (hydr)oxides: structural mechanism from ab initio molecular geometries and EXAFS spectroscopy. Geochim. Cosmochim. Ac. 67 (22), 4223-4230.

Simon, S., Courtin-Nomade, A., Vasiliu, A., Sleiman, N., Deluchat, V., 2016. Long-term influence of aeration on arsenic trapping in a ZVI/sand bed reactor. Rsc Adv. 6 (59), 54479-54485.

Skoropata, E., Desautels, R.D., Chi, C.C., Ouyang, H., Freeland, J.W., van Lierop, J., 2014. Magnetism of iron oxide based core-shell nanoparticles from interface mixing with enhanced spin-orbit coupling. Phys. Rev. B 89 (2), 9.

Tanboonchuy, V., Hsu, J.-C., Grisdanurak, N., Liao, C.-H., 2011. Gas-bubbled nano zero-valent iron process for high concentration arsenate removal. J. Hazard. Mater. 186 (2-3), 2123-2128.

Tian, H., Jing, C., 2014. Genome sequence of the aerobic arsenate-reducing bacterium Pantoea sp. Strain IMH. Genome Announc. 2 (2) e00267-14.

Tian, H., Shi, Q., Jing, C., 2015. Arsenic biotransformation in solid waste residue: comparison of contributions from bacteria with arsenate and iron reducing pathways. Environ. Sci. Technol. 49 (4), 2140-2146.

Tosco, T., Petrangeli Papini, M., Cruz Viggi, C., Sethi, R., 2014. Nanoscale zerovalent iron particles for groundwater remediation: a review. J. Clean. Prod. 77, 10-21.

Tufano, K.J., Reyes, C., Saltikov, C.W., Fendorf, S., 2008. Reductive processes controlling arsenic retention: revealing the relative importance of iron and arsenic reduction. Environ. Sci. Technol. 42 (22), 8283-8289.

Wang, L., Zhuang, X., Zhuang, G., Jing, C., 2016. Arsenic resistance strategy in Pantoea sp. IMH: organization, function and evolution of ars genes. Sci. Rep. 6, 39195.

Wang, N., Xue, X.-M., Juhasz, A.L., Chang, Z.-Z., Li, H.-B., 2017. Biochar increases arsenic release from an anaerobic paddy soil due to enhanced microbial reduction of iron and arsenic. Environ. Pollut. 220, 514-522.

Wang, Y., Morin, G., Ona-Nguema, G., Brown Jr., G.E., 2014. Arsenic(III) and Arsenic $(V)$ speciation during transformation of lepidocrocite to magnetite. Environ. Sci. Technol. 48 (24), 14282-14290.

Wu, Q., Du, J., Zhuang, G., Jing, C., 2013. Bacillus sp. SXB and Pantoea sp. IMH, aerobic As(V)-reducing bacteria isolated from arsenic-contaminated soil. J. Appl. Microbiol. 114 (3), 713-721.

Xie, Y., Dong, H., Zeng, G., Tang, L., Jiang, Z., Zhang, C., Deng, J., Zhang, L., Zhang, Y. 2017. The interactions between nanoscale zero-valent iron and microbes in the subsurface environment: a review. J. Hazard. Mater. 321, 390-407.

Yan, L., Wang, W., Li, X., Duan, J., Jing, C., 2016. Evaluating adsorption media for simultaneous removal of arsenate and cadmium from metallurgical wastewater. J. Environ. Chem. Eng. 4 (3), 2795-2801.

Yan, W., Ramos, M.A.V., Koel, B.E., Zhang, W.-X, 2012. As(III) sequestration by iron nanoparticles: study of solid-phase redox transformations with X-ray photoelectron spectroscopy. J. Phys. Chem. C 116 (9), 5303-5311.

Yang, C., Li, S., Liu, R., Sun, P., Liu, K., 2015. Effect of reductive dissolution of iron (hydr)oxides on arsenic behavior in a water-sediment system: first release, then adsorption. Ecol. Eng. 83, 176-183.

Yang, Z., Shan, C., Zhang, W., Jiang, Z., Guan, X., Pan, B., 2016. Temporospatial evolution and removal mechanisms of $\mathrm{As}(\mathrm{V})$ and $\mathrm{Se}(\mathrm{VI})$ in ZVI column with $\mathrm{H} 2 \mathrm{O} 2$ as corrosion accelerator. Water Res. 106, 461-469. 
Yin, K., Lo, I.M.C., Dong, H., Rao, P., Mak, M.S.H., 2012. Lab-scale simulation of the fate and transport of nano zero-valent iron in subsurface environments: aggregation, sedimentation, and contaminant desorption. J. Hazard. Mater. 227, $118-125$

Zhang, L.H., Birch, R.G., 1997. The gene for albicidin detoxification from Pantoed dispersa encodes an esterase and attenuates pathogenicity of Xanthomonas albilineans to sugarcane. Proc. Natl. Acad. Sci. U. S. A. 94 (18), 9984-9989.

Zhang, X., Jia, Y., Wang, S., Pan, R., Zhang, X., 2012. Bacterial reduction and release of adsorbed arsenate on Fe(III)-, Al- and coprecipitated Fe(III)/Al-hydroxides. J. Environ. Sci. 24 (3), 440-448. 